\title{
Morfosemántica y morfopragmática en alemán y español
}

Estudio contrastivo en torno a la derivación

\author{
Latura Ramíriž SáinZ \\ Universität Tübingen
}

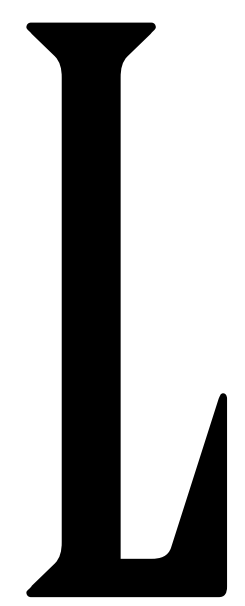

a multiplicidad de significados y funciones de los sufijos diminutivos, elementos de la derivación que trataremos en este breve estudio, son de sobra conocidos. ${ }^{1}$ En este sentido, numerosos lingüistas han realizado ya, tanto en el caso del español como en el del alemán, propuestas clasificatorias. Entre ellos están Alonso (1951), ${ }^{2} \mathrm{Zu}-$ luaga Ospina $(1970)^{3}$ Cartagena y Gauger $(1989)^{4} \mathrm{y}$ Klimaszewska (1983). ${ }^{5}$

Todos estos enfoques han señalado los valores del sufijo diminutivo, y, con ello, su dependencia del contexto y, en cierto sentido, su dimensión pragmática. Ésta se reconoce en español por primera vez con Alonso (1951). La dificultad que presentan los antiguos estudios pragmáticos consiste en que éstos se vinculan a la connotación del sufijo, a un valor concreto «secundario" que confiere al derivado un significado oculto y variable. No obstante, esta orientación tiene una explicación que se entiende tras un análisis de la situación de la lingüística en los años 50. Dado que al diminutivo entonces se le adjudica fundamentalmente un valor nocional, investigadores como Alonso se dedican al estudio del contexto y de la pragmática con el objetivo de atestiguar ejemplos del diminutivo axiológico, el sufijo, por contraposición, connotativo. El peligro derivado de este enfoque fue igualar la pragmática a la connotación, consecuencia ya presente con Alonso y Sieberer y que, según Dressler/Merlini Barbaresi, se repite en Klimaszewska. Si Spitzer y Sieberer recalcaban la connotación expresiva de obligado reconocimiento del sufijo diminutivo, Alonso le concedía, además, un uso estratégico, sólo analizable desde un punto de vista pragmático.

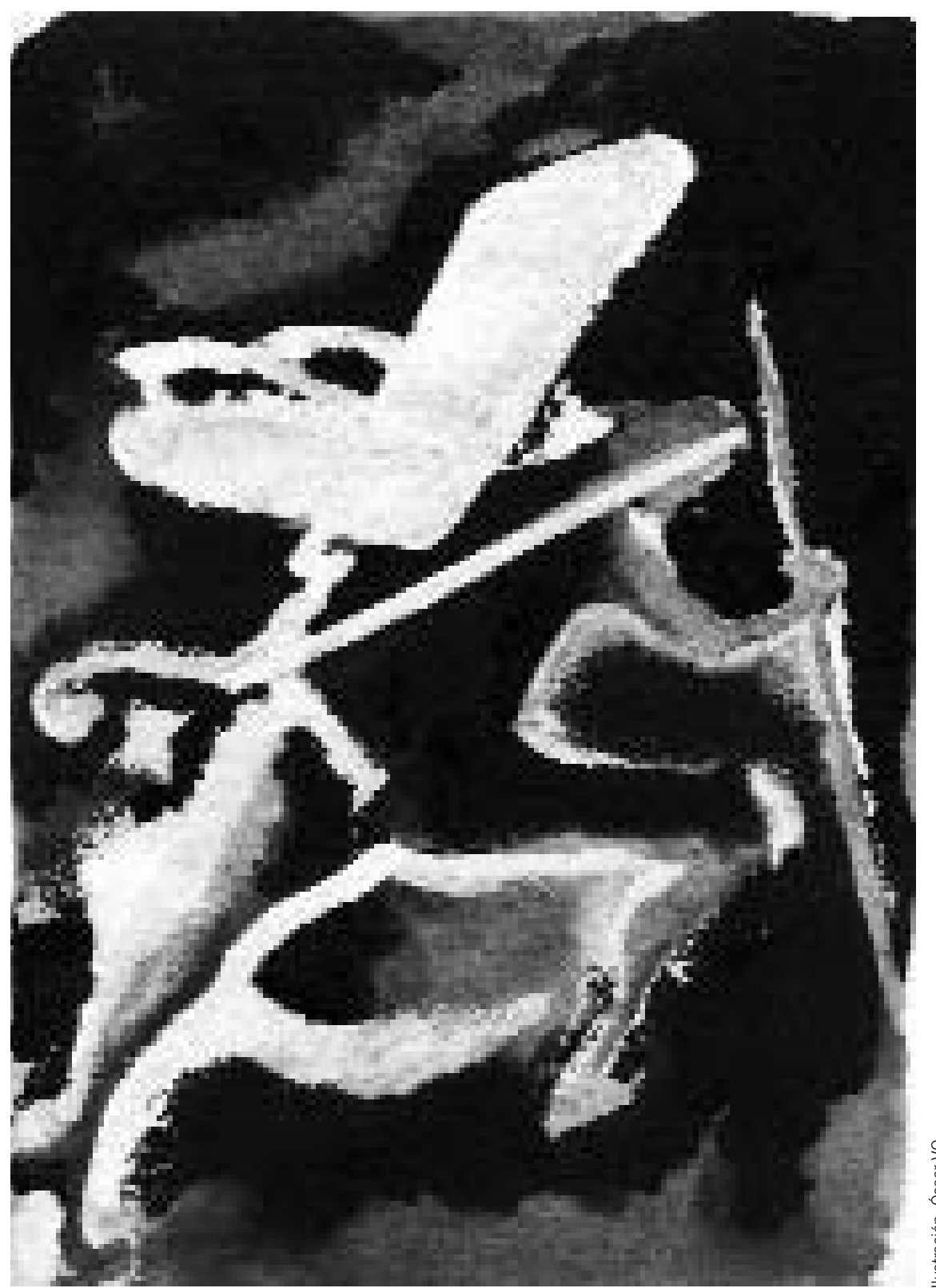

De esta misma forma, adoptando el enfoque del uso del diminutivo como instrumento estratégico y la importancia del análisis de cotexto y contexto en este sentido, parten Dressler/Merlini Barbaresi en su obra Morphopragmatics. Diminutives and In- 
te, una connotación morfopragmática .

tensifiers in Italian, German, and Other Languages (1994). El análisis de estos autores se basa en las teorías de los actos de habla para asignar al sufijo diminutivo una función y un valor en el complejo entramado de la intencionalidad y efectividad. El modelo propuesto se fundamenta en Austin (1962), Searle (1969) y fudamentalmente Searle/Vanderveken (1985). Dressler/Merlini Barbaresi defienden un enfoque pragmático que subdividen, según dos consideraciones conceptuales, en morfosemántica y morfopragmática. Dentro de la primera, los autores diferencian dos valores: [pequeño], cuantitativo, de referencia a un tamaño, y [agradable, etc.], cualitativo, de referencia a una emoción. La segunda se refiere a un valor [no serio] en una situación de habla que permitiría la aparición del diminutivo.

Empezaremos por reconocer la existencia de los dos valores morfosemánticos del sufijo diminutivo. El valor morfsemántico denotativo queda claro ante la siguiente imagen que propone Hasselrot (1957) precisamente como prueba de la presencia de este valor, sin cuya existencia no se produciría jocosidad en la interpretación. La contraposición entre referente (grande) y valor (pequeño) originan una reacción jovial en el receptor. ${ }^{6}$

Ahora bien, partiendo del ejemplo ¡Oh, madrecita mía!, sería el valor denotativo el que quedaría invalidado como posible interpretación, en favor de un uso axiológico, pues, ante esta exclamación «nadie cree que se trata de una pigmea de corta edad y talla leve. Todos ven en aquella frase únicamente la expresión de cariño de un hijo que, llamando «madrecita» a su progenitora, se ahorra una serie de calificativos directos o perifrásticos» (Cornejo, 1973: 42).

Ante la existencia y constatación de dos valores irreconciliables, se plantea la primera y ya antigua dificultad metodológica y conceptual de aunar ambas funciones del diminutivo. El modelo propuesto por Dressler/Merlini Barbaresi se plantearía las concomitancias de estos dos ejemplos en función de la situación de habla en que surge y así llegaría a deducir un valor para el sufijo diminutivo.

Dado que los autores desarrollan un análisis contrastivo entre las lenguas alemana e italiana, en este artículo nos hemos propuesto, entre otros objetivos, una aplicación del mismo al español. Dejamos una aplicación sistemática y exhaustiva para un marco de mayor envergadura. En lo siguiente secundaremos el enfoque propuesto y haremos hincapié en el carácter del sufijo diminutivo y sus funciones como elemento estratégico. La conclusión de Dressler/Merlini Barbaresi, que expondremos también aquí, la compartimos en gran medida para el caso del sufijo diminutivo en español. El análisis del rompecabezas de la expresi- vidad habría encontrado, así, un enfoque que le permitiría ser explicado sistemática y razonablemente, sin indemostrables discusiones terminológicas e insistentes defensas estructurales.

\section{El modelo de Dressler/Merlini Barbaresi}

Dressler/Merlini Barbaresi diferencian entre una denotación morfosemántica, una connotación morfosemántica y una, la más importante, morfopragmática (Dressler/Merlini Barbaresi 1994: 116). Esta tercera dimensión del sufijo diminutivo no excluiría los demás valores, sino que podría actuar de forma conjunta con cualquiera de ellos o, incluso, con los dos de forma simultánea (Dressler/Barberini 1994: 141).

Ante la primacía de uno de los valores sobre el otro, los lingüistas toman partido y mantienen que este acercamiento no da cuenta de la realidad lingüística del sufijo diminutivo. Así, comparan una visión maximalista versus una minimalista; la primera de ellas consistiría en la predominancia del significado denotativo, con la correspondiente subordinación de los demás significados, que pertenecerían a la pragmática (siguiendo la argumentación de que la connotatividad puede ser derivada de la contextualidad). Esto llevaría a que todas las connotaciones estables del diminutivo fueran, por lógica, lexicalizaciones, lo cual no es el caso.

Desde el punto de vista minimalista, existirían denotación y connotación como morfosemántica y todos los usos morfopragmáticos se podrían derivar de ellos. Según Dressler/Merlini Barbaresi la morfosemántica hipotética de los diminutivos es cuestionable, debido a que, por una parte, el carácter denotativo del sufijo diminutivo es en italiano y alemán igual, y por ello quedaría sin explicación la diferencia de sus usos pragmáticos; por otra parte no todos los contextos morfopragmáticos tienen una coloración emocional - numerosos usos del sufijo diminutivo, fácilmente reconocibles, como la ironía, el sarcasmo o la infravaloración; además de que es imposible expresar emociones profundas con el uso del sufijo diminutivo (Schätzchen) (cf. Dressler/ Merlini Barbaresi 1994: 149-150).

La valoración del diminutivo puede ser negativa o positiva, si bien suele tender hacia una interpretación positiva - esto es claro en combinaciones de bases de significado negativo donde el sufijo proyecta sobre el derivado un resultado atenuado (Dressler/ Merlini Barbaresi 1994: 161), en español, por ejemplo, en Una novela flojita a la que le tengo cariño (cf. Rainer, 1993: 585). También es posible en ambos idiomas la dirección inversa. En alemán, sobre bases sustantivas positivas que designan profesiones, el sufijo diminutivo suele designar peyoración (Doktorchen), 
debido a la diminución de la valía profesional del afectado (Dressler/ Merlini Barbaresi 1994: 163). Según Rainer, en español, debe indicar una profesión masculina (empleadito), pues, en el caso de tratarse de una profesión femenina se entiende como expresividad de un afecto: la ex maestrita del jardín de infancia (cf. Rainer 1993: 582). Mediante estos ejemplos, inmersos en un contexto, queda claro que es imposible atribuir al sufijo un valor positivo o negativo estable. Éstos dependen de sus bases léxicas, sus referentes, sus contextos o cotextos y de los actos de habla en los que ocurren (Dressler/ Merlini Barbaresi 1994: 168). Además de ello, en español existe una serie de sufijos que a su vez confieren matices diferentes al derivado. El sufijo -illo supone una estima directa, -ete un aprecio burlador, capaz de resultar positivo o de despreciar. La diferencia amiguillo-amiguete puede poner de manifiesto este aspecto: «Un hombre se reúne con sus amiguetes en su peña, pero no con los amiguillos (menos aún con los amiguitos). Amigos, para quien se refiere a los suyos, significa ya el afecto en alto grado; amiguillo habrían de ser o unos niños (pero entonces no constituirían su peña) o unos hombres considerados con tan súbito afecto que la mesura varonil lo rechaza. Amiguetes resuelve la cuestión: esos compinches de bar son nombrados con estima y con humor bastante simultáneos» (Lázaro Mora, 1999: 4677).

Dressler/Merlini Barbaresi proponen dos niveles abstractos diferentes: uno para la morfosemántica y otro para la morfopragmática. De la semántica se derivarían valores como [pequeño, no importante, ate-

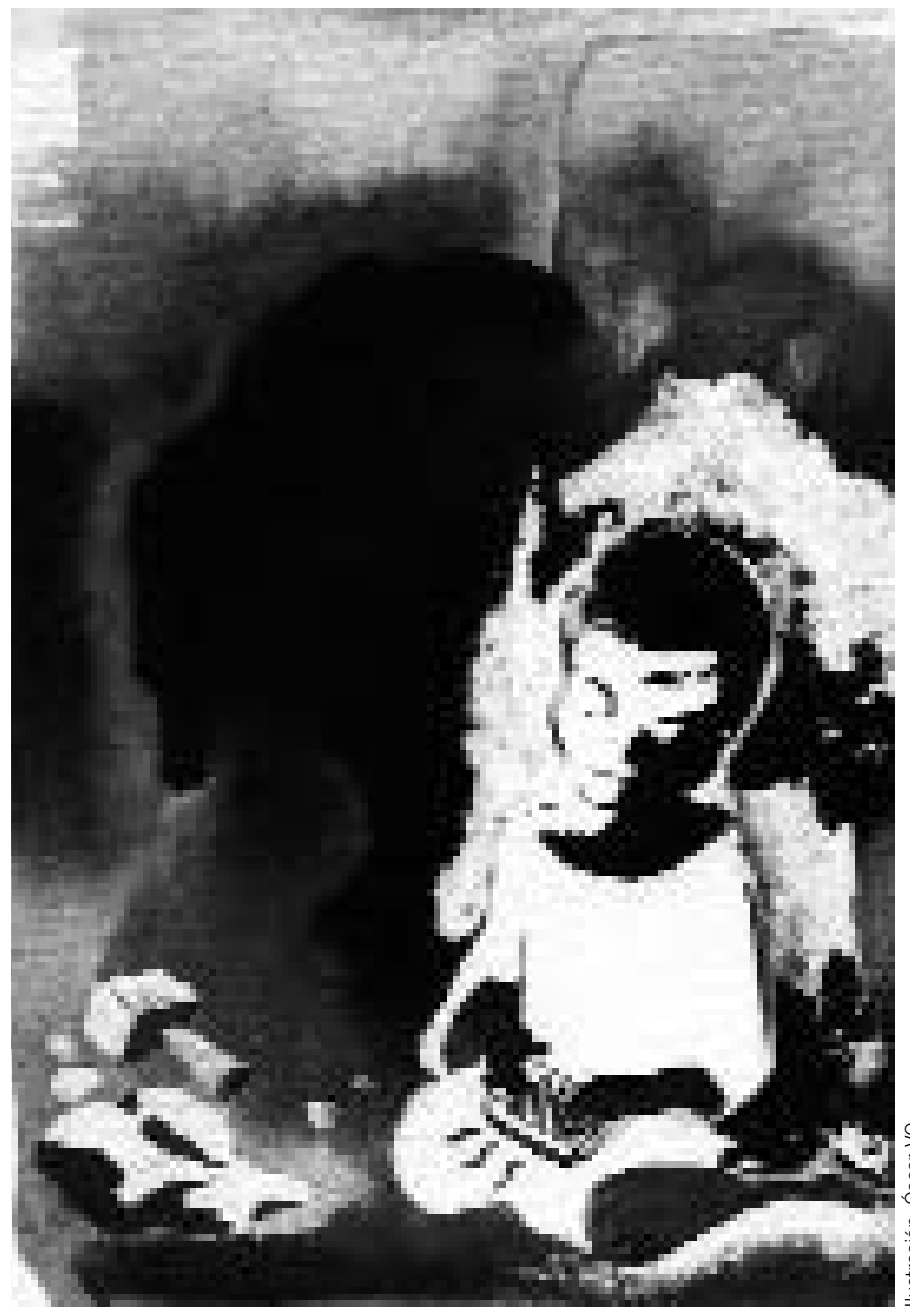

sufijo diminutivo nunca aparezca en sentencias y cláusulas, que sea usual en las oraciones de tipo lúdico, que se utilice como estrategia de atenuación en actos de habla desagradables como peticiones, órdenes, recriminaciones y amenazas. Además de ello, existirían las formas de eufemismo, infravaloración y modestia con respecto a uno mismo, la ironía con respecto a otro, en interacción cooperativa, a distinción del sarcasmo en interacción antagonista (Dressler/Barberini 1994: 146-7).

\section{Situaciones de habla}

Dressler/Merlini Barbaresi explican el componente indiscutiblemente positivo de los sufijos diminutivos en base a cuatro formas de aparición que presentan y que podrían condicionar o ser una explicación de su uso y significado y que ellos aúnan en un grupo. En él, el diminutivo se refiere a niños y posee connotación positiva, a mujeres u hombres y viceversa, cuyo uso prototípico tiene lugar en la familia (caracterizado por la presencia de sentimientos positivos), $y$ una cuarta clase en la que se incluirían los animales (cf. Dressler/Merlini Barbaresi 1994: 165166).

El caso del diminutivo utilizado con niños como receptores puede ser interpretado como aplicación semántica de la característica denotativa [pequeño] o como realización de la característica pragmática [no serio]. En el primer caso se produciría una transformación de la característica denotativa en dirección de la característica pragmática. En el segundo, la característica [no serio] estaría presente desde el principio a causa de que el receptor es un niño considerado adulto, hablante prototípico por definición, y capaz de interpretar adecuadamente el acto de habla. nuado...]; de la pragmática se derivarían los allopragms. No se necesitaría diferenciar una connotación, pues ésta se derivaría de la pragmática, diferente en cada lengua. El sufijo diminutivo actuaría, en realidad, aunque forme parte de los semas de la palabra, sobre el acto de habla completo, aunque no pertenecería ni sería característica del acto de habla en sí mismo. Los autores asumen que el sufijo diminutivo posee un carácter general [no serio], el cual se utiliza como estrategia para disminuir la responsabilidad del hablante sobre el acto de habla que utiliza. Ésta sería la característica morfopragmática del sufijo diminutivo (Dressler/Merlini Barbaresi 1994: 144). Así se explicaría que el
En estas situaciones el niño es el hablante, el receptor o un participante indirecto. Prototípicamente es de corta edad - de hecho, la formación diminutiva es una de las primeras operaciones de morfología gramatical que adquieren los niños. Dentro de estas situaciones se observan comportamientos diferentes en las lenguas. En alemán, a diferencia del español, se reserva a esta etapa un sufijo determinado (-i). El diminutivo «infantil» puede aparecer con cualquier acto de habla, bien de forma directa, bien de forma indirecta (Heute essen wir Eili. ¿Quieres fresitas hoy?), lo cual muestra nuevamente lo situaciónal del sufijo (cf. Dressler/ Merlini Barbaresi 1994: 173-176). 
Otra característica de la situación es la distancia entre el hablante y el objeto (Seid's keine solchen Dummerln) y la empatía (Hast du dir am Haxerl weh getan, ¿Te has hecho daño en la rodillita?). La relación entre el uso pragmático y el uso semántico en ambos idiomas en estas situaciones se explica a partir de la relación entre las características [pequeño] y [no serio] (cf. Dressler/Merlini Barbaresi 1994: 183-188). Como más adelante publicaría Hummel, aquí estaríamos ante el uso prototípico donde ambos valores actúan recíprocamente (1997)

Con respecto a las situaciones con animales (Pet-centered speech situations) o con enamorados (Lover-centered speech situations) las explicaciones pasan por la interpretación de la existencia de cierta analogía entre las situaciones; en el primer caso debido a que los animales pueden ser tratados como niños (Hundi, Pfötchen geben); en el segundo, según explicación freudiana, a causa de los «kindischen Geste aller Verliebten» (brunnette) (cf. Dressler/Merlini Barbaresi (1994: 191-6), que interpretaría Quiroga en una de sus obras de igual manera Volvía con su mujer "mi mujerciña, pensaba, ruborizándose del diminutivo (E. Quiroga, Viento del Norte, 169, en De Bruyne, 2000: 607).

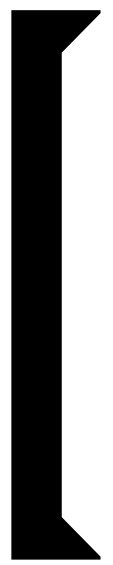

Los autores parten de que los elementos emotivos en los sufijos diminutivos son secundarios y difíciles de clasificar. Junto a emociones intensas se produce un bloqueo en el uso del diminutivo que los lingüistas entienden por el valor Ino seriol del suffijo diminutivo.

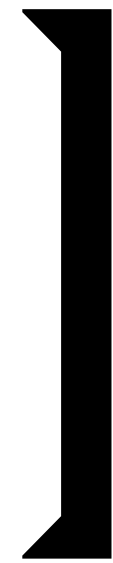

\section{Factor: Carácter lúdico de juego}

Este significado pragmático puede originarse mediante la derivación sobre bases elevadas, abstractas que normalmente no permitirían la sufijación diminutiva (cf. Dressler/Merlini Barbaresi 1994: 200-201), en español también sobre bases inusuales por motivos morfológicos: "¿Por qué cree que en España existe actualmente un "boom» del humor?» «En España, amigo mío, todos son «boom»: "boom» de humoristas, «boom» de novelistas hispanoamericanos», "boom» de jóvenes novelistas españoles, [...], «boom» del Opus, «boom» de idiotas de toda laya que no cesan de interesarse por el último «boom». A ver cuando hay un "BОООООМММММ» bien gordo, de los que no dejan a nadie indiferente, y asi acaba la pasión por los «boomecitos» (Cita de Fernando Savater en Polo, 1975: 21), y por motivos léxicos: "Una brújula es una viéjula montada en una escóbula» (cf. Zuluaga Ospina, 1970: 26) o "¿Qué es una (b)oreja?» «Sesenta minutejos».

\section{Factor: Emocionalidad}

Los autores parten de que los elementos emotivos en los sufijos diminutivos son secundarios y difíciles de clasificar. Junto a emociones intensas se produce un bloqueo en el uso del diminutivo que los lingüistas entienden por el valor [no serio] del sufijo diminutivo. En caso de aparecer un diminutivo en un contexto emocional de este tipo se usa con el fin de cumplir un efecto atenuante (Dressler/Merlini Barbaresi 1994: 204-205). Como señalaba Sieberer en los años 50, «Ziehen wir die mächtigen Dinge und Tiere kraft der diminutiven Namen an uns heran, so verlieren sie damit einen Teil ihrer Gefährlichkeit. Wir dürfen erwarten, dass die in ihnen verborgenen Wesenheiten nichts unternehmen werden gegen ihre Freunde, die sie so zuvorkommend aussprechen» (Sieberer, 1950-51: 111). Gooch habla de la reducción de las cosas a tamaños que nos resultan agradables y cita a García Lorca: «No queremos que el mundo sea tan grande ni el mar tan hondo. Hay necesidad de limitar, de domesticar los términos intensos» ${ }^{8}$ (García Lorca, 1957: 3). Seidel-Slotty (1947) recoge ejemplos diminuidos de animales peligrosos que nosotros documentamos en la literatura: «Ese piso feliz por el que viborillas perspicaces hacen su nido» (Aleixandre, Gedichte 26).

\section{Factor: Simpatía y antipatía}

Éstos, en cambio, son conceptos más claros; en parte porque son directos y en parte porque revelan un intercambio interactivo entre hablante y oyente, que a su vez indica la afinidad del hablante (cf. Dressler/Merlini Barbaresi 1994: 206). En Cela encontramos simpatía en varias direcciones: del autor hacia un personaje, Don Ricardo Sorbedo es un hombre pequeñito, de andares casi pizpiretos, de ademanes grandilocuentes y respetuosos, de hablar preciso y ponderado, que construye muy bien sus frases, con mucho esmero (Cela, La Colmena 278), de un personaje hacia una futura situación: Un nietecito sacerdote que nos edifique a todos con su virtud (Cela, La Colmena 302). Una variante de la simpatía es, según estos autores, la compasión: Doña Jesusa dio en el hombro a una de las chicas que se calentaban al fuego, a una muchachita flacucha que estaba leyendo una novela (Cela, La Colmena 257). Sería interpretable compasión por la profesión de la muchacha, la prostitución, si bien en este caso sería posible reconocer una simpatía del autor por la afinidad con la muchacha en su afición por la lectura.

\section{Factor: Formalidad-familiaridad}

Como otro factor del sufijo diminutivo señalan Dressler/Merlini Barbaresi los ambientes formales, familiares e íntimos. En este sentido se revelarían las primeras diferencias entre el uso del sufijo diminutivo en las diferentes lenguas. Familiaridad e intimidad parecen deber estar en mayor grado presentes para favorecer el uso del sufijo diminutivo. El uso del sufijo diminutivo en situaciones formales es en alemán practicamente inviable.

Dressler/Merlini Barbaresi señalan la imposibilidad de derivar la relevancia de la formalidad, familiaridad o intimidad bien de una interpretacion emocional del sufijo diminutivo, bien de una característica nocional. Sí, en cambio, sería plausible considerar la característica [no serio] de la situación de habla que favorece la aparición del sufijo diminutivo. En el primer caso se produce una disminución de la distancia psicológica, a su vez permitida por el 
interlocutor. Hay simpatía, familiaridad, intimidad. En este sentido, el discurso perdería su carácter [serio] (cf. Dressler/Merlini Barbaresi 1994: 218). Un posible ejemplo en español de este cambio de familiaridad a formalidad lo recogería De Bruyne de García Márquez: "Esto es un disparate, Aurelito» "No me vuelva a llamar Aurelito, que ya soy el coronel Aureliano Buendía [...]» [Aureliano Buendía hat seinem Schwiegervater gerade mitgeteilt, daß er auf Seiten der Gegenpartei am Bürgerkrieg teilnehmen wird. Den Gebrauch einer Diminutivform asoziiert er scheinbar zu sehr mit seinem früheren Status eines braven Schwiegersohns, mit seiner neuen Situation als einem rebellierenden Offizier scheint er dagegen nicht vereinbar]» (en De Bruyne, 2002: 583). El coronel Buendía no quiere ser tratado en un tono familiar, sino formal, en el que pueda representar su status de coronel.

\section{Factor: Landing -site}

Con este término los autores se refieren a un uso menos frecuente en alemán que en otras lenguas a causa de las incompatibilidades morfológicas y léxicas de los sufijos diminutivos y las bases derivadas (cf. Dressler/Merlini Barbaresi 1994: 219). El ejemplo clásico en español es El niño nació cieguito, que como apunta De Bruyne podríamos traducir al alemán como «das Kindchen wurde blind geboren' aber eine Bildung wie "das Kind wurde blindchen geboren» ist nicht möglich» (cf. De Bruyne, 2002: 575). En español aparece simultáneamente algún tipo de simpatía, empatía, compasión.

\section{Actos de habla Peticiones}

El uso del sufijo diminutivo en peticiones se puede interpretar como debilitamiento (Schreib mir ein Stückchen Text), estrategia pragmática (Venga usted un momentito / Könntest Du bitte ein Momenterl kommen?), o cortesía (Me podrías traer un cafetito?). Dentro de ésta existirían dos tipos (positiva y negativa), ambas susceptibles de ser reforzadas mediante el sufijo diminutivo. La formulación negativa expresaría cierto pesimismo (real o no) con el objetivo de formular una petición de igual modo. En la variante positiva de la cortesía los sufijos diminutivos podrían actuar como elemento acelerador en la creación de una situación familiar. Igualmente servirían en la búsqueda de acuerdo o en la forma de eludir el desacuerdo y podrían suavizar una propuesta en la que en la que se pretende una cooperacion ente hablante y receptor: Komm, setzen wir uns zu einem kleinem Plauscherl (Dressler/ Merlini Barbaresi 1994: 229-234). En español, la interpretación de Alonso se acercaba ya mucho a este enfoque: «Entre usted despacito, vaya deprisita, no suponen más lentitud ni más celeridad que despacio y de prisa; son simplemente más corteses o más recomendativos» (Alonso, 1951: 1645). Según Náñez Fernández, con los sufijos de cortesía se pretende ganar el afecto del interlocutor. Es «un gesto vivo de afecto convertido por el trato social en un ademán convencional. Se emplea la forma expresiva del cariño cuando no hay ni la pretensión de cariño. Justamente en lo que consiste la mera cortesía» (Náñez Fernández, 1973: 125).

La característica morfopragmática [no serio] estaría presente en este caso (Dressler/Merlini Barbaresi 1994: 237-8). La relación entre la cortesía, la afectividad y la recomendatividad de que hablaban Alonso y Náñez Fernández se explica, en parte, por el valor [no serio], que es el valor común a la emotividad (gesto vivo de afecto de Náñez Fernández) y a la cortesía, donde los sufijos diminutivos actúan como aceleradores de una situación familiar con motivos pragmáticos. Esto es lo que tienen en común y esto explicaría las interpretaciones. Cabe plantearse una relación metonímica según el valor morfosemántico [agradable], según la interpretación de Náñez Fernández. En caso de las peticiones, solicitudes e imposiciones el diminutivo reduciría la fuerza autoritaria del hablante, pero no modificaría el acto de habla (cf. Dressler/Merlini Barbaresi 1994: 241-5).

Dentro de este grupo interpretan Dressler/Merlini Barbaresi la petición de limosna de los mendigos (Deme un pedacito de pan), en el que el hablante rebaja la fuerza de la petición mediante un diminutivo y simultáneamente consigue mayor eficacia en sus propósitos. La carencia de familiaridad bloquearía el uso del sufijo diminutivo en alemán. Habría que plantearse si, además, se apelan a otros sentimientos en este tipo de requerimiento como la compasión, la empatía, etc. Como recoge Fernández Ramírez, «no será preciso recordar, en fin, que en el sufijo diminutivo se acumulan frecuentemente sentimientos de piedad, de conmiseración, una modalidad de la ternura y del afecto y que abundan los viejecitos, los pobrecitos, los derrengaditos» (Fernández Ramírez 1962: 188). Igualmente lo reconocía Alonso: «Un mendigo, por ejemplo, que pide una limosnita, no expresa su estado de ánimo, sino que pretende originar un sentimiento de compasión en los que le rodean para obtener un resultado que él espera (cf. Alonso, 1951: 171), e incluso Cela en una de sus obras "-¿Quiere usted traer una jarra de agua fresquita? Los poetas, cuando piden agua, dicen siempre fresquita. Así, en diminutivo, queda más íntimo, más cariñoso y hay más probabilidades de que, por lo menos por compasión, le hagan caso a uno. [...] Por favor ¿puede usted darme un poquito de bicarbonato? Los poetas, cuando quieren bicarbonato, lo piden siempre por favor, y dicen: un poquito, para no alarmar. Las fórmulas de mendigo suelen estar acreditadas de eficaces" (Cela, El molino, 627). A pesar de que Dressler/ Merlini Barbaresi mantienen el valor morfopragmático [no serio], nuevamente sería posible la relación metonímica según el valor morfosemántico [agradable].

\section{Consejos}

Como ejemplo prototípico de los consejos proponen Dressler/Merlini Barbaresi Warum wartest du nicht lieber ein Stündchen, bevor du ihn anrufst?, donde el efecto atenuante sería menos claro dado que el hablante quiere obtener un resultado en su propio beneficio pero a costa del receptor.

\section{Valoración}

Como ya hemos señalado anteriormente, el sufijo diminutivo puede tener un efecto mitigador de una valoración negativa $(\mathrm{Da}$ gibt es ein ganz schönes Bergerl), expresar una actitud positiva hacia el objetivo descrito, (Was für ein schönes, fröhliches $M u$ sikstückerl!), empatía (Da haben Sie noch ein Lückerl) (dentista al paciente) y, en este caso incluso tranquilizar a causa del consiguiente tratamiento médico (el médico se anticipa al paciente) (cf. Dressler/ Merlini Barbaresi 1994: 263-267). Los diminuti- 
vos pueden ser evaluativos y expresivos (Was für ein Weinchen), enfatizar (Was für ein Wagerl!), o servir de aviso (Achtung, bissiges Hündchen) (Dressler/ Merlini Barbaresi (1994: 280-284). Existirían en español todos estos usos, a excepción del último, que apuntaría más hacia la ironía causada por la contraposición [pequeño] y la característica [peligroso]. Como ejemplo de actitud positiva hacia el objeto, citaremos el siguiente: «Estaba la atardecida tan calma, que el aroma de las flores verduras preñaba mucho el ambiente. Alrededor de las luces revolaban insectos jubilosos. Y de cuando en cuando se oía una risa juvenil, un gritillo lejano» (García Pavón, Geschichten 26).

Las disculpas en alemán se limitan al uso familiar (Entschuldige bitte, das war nur ein Späßchen) y en los agradecimientos o las felicitaciones, incluso en estilo indirecto también es posible el uso del diminutivo (Danke für das reizende Geschenkerl) (Dressler/Merlini Barbaresi 1994: 288). Las declaraciones y las lamentaciones, por lo general, son demasiado serias como para utilizar un sufijo diminutivo (Dressler/Merlini Barbaresi 1994: 285-292).

El sufijo diminutivo puede aparecer también en fórmulas de bienvenida, en saludos con carácter lúdico (Tagchen), en promesas (Ich versprech dir ein Briefl zu schreiben), en las que la importancia del compromiso puede ser modificada por el sufijo di-

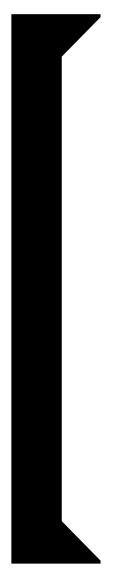

Las disculpas en alemán se limitan al uso familiar (« Entschuldige bitte, das war nur ein Späßchen") y en los agradecimientos o las feliciticiones, incluso en estilo indirecto también es posible el uso del diminutivo (“Danke fuir das reizende Geschenkerl»).

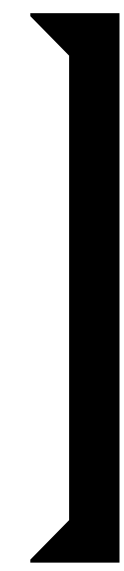

minutivo (Dressler/ Merlini Barbaresi 1994: 294- 296). También pueden estar presentes en amenazas (Warte nur Kerlchen, das werde ich dir zeigen); que reciben el mismo tratamiento que las promesas - incluso el verbo performativo prometer se puede entender también como amenaza en español y en alemán (cf. Dressler/Merlini Barbaresi 1994: 298). Los autores identifican la característica [no serio] por el hecho de que el receptor no se considera un oponente serio, aunque cabría también una interpretación de ironía. La apuesta requiere también un verbo performativo y supone un compromiso serio por parte del hablante, por ello, igual que las ofertas, podrían bloquear el uso del diminutivo, si el ambiente fuera muy formal. En caso de poder ser utilizado el diminutivo (Ich möchte ein hübsches Sümmchen wetten. Ich kaufe dir dein Wagerl ab, wenn du mir einen guten Preis machst), se debería interpretar como empatía, familiaridad o, incluso ironía, si el referente y el sentido denotativo no se corresponden (Dressler/ Merlini Barbaresi 1994: 302). En el caso Por cinco duros te puedo dar uno que tiene gracia. [...]. Además lo tengo con mar- quito y todo, asi lo compré. Si es para un regalo te viene que ni pintiparado (Cela, La Colmena 304), también estamos ante un valor [no serio].

Además de ellas, existirían las ofertas con compromiso, entre las cuales se podría entender un menú de un restaurante - como compromiso que contrae el restaurante por ofrecer algo que anuncia. La recomendación puede igualmente estar presente (Ich könnt' Ihnen da ein Weinderl empfehlen!) Según los autores, los sustantivos diminuidos suelen expresar en estas circunstancias, a diferencia del español, un valor nocional Darf ich Dir ein Schnapserl geben? (Dressler/ Merlini Barbaresi (1994: 303-304).

\section{Uso figurativo de los actos de habla}

En primer lugar, los autores señalan la modestia (Mein Kapitelchen) en sentido atenuativo, y de igual incidencia en español: «Se usa principalmente en las introducciones a las obras que sus autores llaman cosillas, romancico, tratadillo, librillo» (Latorre, 1956: 113). Una distinción se refiere al componente atenuante de -illo; Lázaro Mora (cf. 1981: 487) señala este contraste a partir del siguiente ejemplo: "Yo -comentaré con mis amigos- estoy escribiendo un articulillo (incluso un articulejo), para restar énfasis e importancia a mi acción. Un articulito manifestaría, como articulillo, lo reducido del trabajo, pero mi adhesión a él sería totalmente positiva». Cabe interpretar que el uso del sufijo diminutivo se estima como apropiado antes de ser utilizado y sólo será utilizado en situaciones formales cuando el hablante considere que será interpretado adecuadamente, por ejemplo, en este caso, entre colegas y compañeros de profesión, Una situación de habla diferente tendría lugar, por ejemplo, en el caso de que el hablante hubiera de presentar los resultados de sus investigaciones ante un proceso de evaluación.

En segundo lugar, el diminutivo puede servir al eufemismo (Sie haben ein Paar Fehlerchen gemacht (cf. Klimaszewska, 1983: 56)), o, en español, un ejemplo de Alonso reproducido en Dressler/Merlini Barbaresi (1994: 330), Singando/ Silencio!, use un lenguaje más decente!/ Bueno, pues singandito.

Y en tercer lugar, el diminutivo permite la creación de ironía y sarcasmo. La ironía se puede originar mediante la contraposición entre el carácter [pequeño] y el referente, si este no fuera pequeño, como en el caso Dein Freund bat mich ihm das Sümmchen von $\$ 100.000$ zu leihen, mediante contraposición [bonito] y la intención expresada, por ejemplo en Bien que le oí al Aróstegui ese, y parece un muchacho educado, ya ves, que «la libertad era como una puta en manos del dinero", Mira que palabritas, y ni disculparse cuando me vio (contraposición de palabritas - palabras malsonantes), mediante el significado abstracto de la palabra base, que, por lo general, se resistiría a la diminutivización (Dressler/Merlini Barbaresi 1994: 341-343) en Jede Betätigung auf dieser Kugel hat sich eine Wissenschaft als Dach aufgebaut... Und die Pfaffen all dieser Wissenschäftchen sind munter am Werke (Tucholsky, K., Werke, en Klimaszewska 1983: 58), mediante la contraposición de familiaridad versus formalidad, (en una obra de análisis bibliográfico sobre la formación de palabras), Estudio de conjunto de la formación de palabras en español desde la perspectiva de un funcionalismo inspirado por E. Coseriu y B. Pottier-con el cual comparte también la afición por los dibujitos (Rainer 1992: 65), mediante la contraposición 
entre la sinceridad de un deseo y el carácter no serio del diminutivo, Ich wäre Ihnen herzlich dankbar, wenn Sie dieses Feuerl austreten könnten-ohne mich dabei als ganzes zu zerteten, o incluso mediante la expresión de la autoironía (declaración de un emigrante judío que debió abandonar Viena en 1938) «So hab, ich mein Kofferl gepackt und bin weg (Dressler/Merlini Barbaresi 1994: 351), o mediante la contraposición de referente y entonación. ${ }^{9}$ La diferencia que ven Dressler/Merlini Barbaresi entre ironía y sarcasmo es la intencionalidad: en el segundo, la intención es herir al oyente, originar irrisión y polémica; en la ironía, en cambio, se persigue más el humor. Por ello existe la ironía (y no el sarcasmo) hacia uno mismo. En la ironía el diminutivo atenúa, en el sarcasmo acentúa. El valor [no serio] indica en la ironía que la interpretación no debe ser literal, en el sarcasmo, en cambio, empequeñecería a la víctima del sarcasmo (Dressler/Merlini Barbaresi 1994: 360-372).

\section{Conclusiones}

El enfoque de Dressler/Merlini Barbaresi mantiene que existe una denotación morfosemántica, una connotación morfosemántica y una morfopragmática. Esta tercera dimensión del sufijo diminutivo no excluiría los demás valores, sino que podría actuar de forma conjunta con cualquiera de ellos $\mathrm{o}$, incluso, con los dos de forma simultánea. Este modelo resolvería la dicotomía clásica y aunaría las funciones del sufijo diminutivo con una única explicación. Todos los usos clasificados por los lingüistas y citados al principio de este artículo en una nota a pie de página gozarían así de una expli-

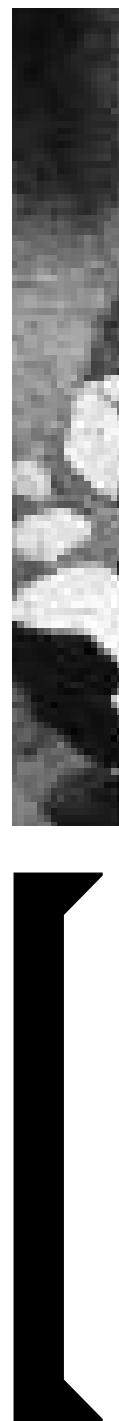

Respecto al enfoque del modelo, creemos que

el análisis del diminutivo en función de los ac-

tos y situaciones de habla justifica y demuestra la función, el valor y la fuerza del sufiljo diminulivo. cación lógica y convincente.

Los sufijos diminutivos pueden modificar la fuerza ilocutiva de los actos de habla pero nunca pueden transformar un acto de habla en otro. Los autores comparan la modificación del sufijo diminutivo con la aportación que realiza un adverbio.

En los actos de habla directivos, los diminutivos tienden a intentar provocar un efecto en el oyente, bien para obligarle, bien para evitar su rechazo. Los diminutivos se esperan más en actos de habla expresivos que en asertivos. Hay actos de habla que no se pueden combinar con diminutivos (declarativos) y en algunos actos de habla la presencia de un verbo performativo podría anular la existencia de un sufijo diminutivo.
En muchas ocasiones se constatan varios actos de habla. La combinación puede estructurarse en 4 tipos: la contribución de cada acto de habla es igual; uno de ellos predomina; el segundo es sólo una introducción, y un modelo sigue las premisas prototípicas de un acto de habla X, pero sirve de acto de habla indirecto Y. Ante esta variable, sólo este segundo puede ser modificado.

Dressler/Merlini Barbaresi hablan de la sobrevaloración que ha tenido lugar sobre el valor emocional de los sufijos diminutivos y lo definen como un accidente pragmático. Ante los valores morfosemánticos [pequeño], [agradable, etc.], y el morfopragmático [no serio], los autores se decantan por el segundo como explicación de la aparición del sufijo diminutivo. Sólo este valor puede dar explicación al uso del diminutivo en un discurso familiar, íntimo, informal o con carácter lúdico.

Respecto al enfoque del modelo, creemos que el análisis del diminutivo en función de los actos de habla y situaciones de habla justifica y demuestra la función, el valor y la fuerza del sufijo diminutivo. Otra cuestión sería si se trata de un movimiento vertical, metafórico, como plantean Dressler/Merlini Barbaresi, es decir, si de los valores [pequeño] y [agradable] derivan en una dirección vertical, metafórica, otros usos; o si se trataría de una relación metonímica, que conllevaría una dirección horizontal, de paralelismo entre situaciones. Las consecuencias de la interpretación metonímica o metafórica sobre el valor morfosemántico y morfopragmático del diminutivo pueden ser solamente apuntadas en este artículo.

Respecto a la clasificación propuesta por Dressler/Merlini Barbaresi para esu estudio contrastivo alemán-italiano constataríamos que en una serie de contextos el comportamiento del sufijo diminutivo en alemán y español es similar (situaciones de habla, el factor del carácter lúdico, la emocionalidad, la simpatía y antipatía), mientras que en otros difiere (el factor familiaridad-formalidad o el así por estos lingüistas llamado Landing-side). Un estudio más exhaustivo a partir de un corpus más extenso aportaría, desde el enfoque de los actos y las situaciones de habla, con seguridad, nuevas e interesantes conclusiones 


\section{Bibliografía}

Primaria

Aleixandre, Vicente (1980): Gedichte, españolalemán. Leipzig: Philipp Reclam. Gedichte

Cela, Camilo José (1992) ${ }^{6}:$ La colmena. Madrid: Cátedra, Letras Hispánicas. Trad. (1988): Der Bienenkorb. München, Zürich: Piper.

García Pavón, Francisco (1990): Kriminalgeschichten, español-alemán. Stuttgart: Philipp Reclam. Kriminalgeschichten

Secundaria

Alemany Bolufer, José (1920): Tratado de la formación de palabras en lengua castellana. Madrid: Suárez.

Almela Pérez, Ramón (1999): Procedimientos de formación de palabras en español. Barcelona: Ariel.

Alonso, Amado (1930): «Para la lingüística de nuestro diminutivo», Humanidades, (La Plata), XXI, 35-41.

(1951): «Noción, emoción, acción y fantasía en los diminutivos», en: Estudios lingüísticos. Temas españoles, Biblioteca Románica Hipánica. Madrid: Gredos, 161-189.

Alvar, Manue/Bemard Pottier (1983): Morfología histónica del español. Madrid: Gredos.

Austin, John (1962): How to Do Things with Words. Oxford: Clarendon Press.

Beinhauer, Werner $(1968)^{2}$ : El español coloquial. Madrid: Gredos.

Berschin, Helmuth/Fernández Sevilla, Julio/Felixberger, Julio (1987): Die spanische Sprache. München: Max Huber Verlag.

Bruyne, Jacques de (1986): «Algunos aspectos de la problemática de la traducción al alemán de los sufijos apreciativos españoles", en Neumeister, S. (ed.): Actas del IX Congreso de la Asociación Internacional de Hispanistas. Frankfurt a. M., S. 93-102.

(2002): Spanische Grammatik. Tübingen: Max Niemeyer Verlag.

Cartagena, Nelson/Gauger, Martin (1989): Vergleichende Grammatik, Spanisch-deutsch T. 2, Dudenverlag, Mannheim, Wien: Institut für deutsche Sprache.

Cornejo, Justino (1973): «Vida y pasión del diminutivo", Yelmo, 12, 42-3.

Coseriu, Eugenio (1987): «La formación de palabras desde el punto de vista del contenido", Gramática, semántica, universales, 23964. Madrid: Gredos.

(1962): Teoría del lenguaje y lingüística general, Madrid: Gredos.

$(1991)^{2}$ : El hombre y su lenguaje Madrid: Gredos.

Dressler, Wolfgang/Merlini Barbaresi, Lavinia (1994): Morphopragmatics. Diminutives and intensifiers in Italian, German, and other languages. Berlín.

Ettinger, Stefan (1974): Diminutiv- und Augmentativbildung: Regeln und Restriktionen. Tübingen: Tübinger Beiträge zur Lingüistik.

Fernández Ramírez, Salvador (1962): «A propósito de los diminutivos españoles", Strenae, t. XVI, 185-192.

(1986): La derivación nominal, Madrid: Real Academia Española.

Fleischer, Wolfgang/Barz, Irmhild $(1995)^{2}$ : Wortbildung der deutschen Gegenwartssprache. Tübingen: Niemeyer.

Gauger,Hans-Martin (1971): Durchsichtige Wörter. Heidelberg: Carl Winter.
Gooch, Anthony, (1970)2: Diminutive, augmentative und pejorative suffixes in modern spanish (A guide to their use and meaning), $\mathrm{Ox}$ ford: Pergamon Press.

Hasselrot, Bengt (1957): Etudes sur la formation diminutive dans les langues romanes, $\mathrm{Upp}-$ sala: Universitet Arsskrift, 11

Hummel, Martin (1997): «Para la lingüística de vuestro diminutivo: los diminutivos como apreciativos», Anuario de Estudios Filológicos, XX, Universidad de Extremadura 191-210.

Klimaszweska,Zofia (1983):Diminutive und Augmentative Ausdrucksmöglichkeiten des Niederländischen, Deutschen und Polnischen. Varsovia: PAN.

Koch, Peter, Österreicher, Wulf (1990): Gesprochene Sprache in der Romania: Französisch, Italienisch, Spanisch, Romanistische Arbeitshefte, 31. Tübingen: Niemeyer.

Latorre, Federico (1956-1957): «Diminutivos, despectivos y aumentativos", Archivo de Filología Aragonesa, VIII-IX, 105-120.

Lázaro Mora, Fernando A. (1999): «La derivación apreciativa», en Bosque, Ignacio/Demonte, Violeta (eds.): Gramática descriptiva de la lengua española. Madrid: Real Academia Española.Madrid:Espasa Calpe, T.3,4647-4682.

Martínez de Morentín, Manuel (1857): Estudios filológicos. Londres: Trübner y $\mathrm{C}^{\mathrm{a}}$.

Motsch, Wolfgang (1999): Deutsche Wortbildung in Grundzügen. Berlin - New York: Schriften des Instituts für deutsche Sprache 8.

Náñez Fernández, Emilio (1973): El diminutivo: historia y funciones del español clásico y moderno. Madrid: Gredos.

Polo, José (1975): «Diminutivos en acción», Español actual, 29, 9-36.

Rainer, Franz (1993): Spanische Wortbildungslehre, Tübingen: Max Niemeyer Verlag.

(1992): «Setenta: (1921-1990) años de investigación en la formación de palabras del español moderno: bibliografía crítica selectiva», en Soledad Varela, La formación de palabras, Madrid: Taurus, 30-70.

Salvá, Vicente (1988): Gramática de la lengua castellana según ahora se habla. Ed. Lliteras, Margarita. Madrid: Arco/Libros.

Seidel-Slotty, Ingeborg (1947): «Über die Funktionen der Diminutiva", Bulletin linguistique, XV, Copenhage-Bucarest, 23-54.

Searle, John (1969): Speech acts: An essay in the philosophy oflanguage. Cambridge, England: Cambridge University.

Searle, J.R., Vanderveken, D. (1985): Foundations of Illocutionary. Logic, Cambridge University Press.

Sieberer, Anton (1950-51): «Das Wesen des Deminutivs", Die Sprache, II, 85-121.

Spitzer, Leo (1937): «Espagnol, spagnuolo, spaniard: Deminutiva und aumentativa bei Ethnica», Travaux du Seminaire de Philologie Romane, Estambul, I, 1937.

Waltereit, Richard (2006): Abtönung. Zur Pragmatik und historischen Semantik von Modalpartikeln und ibren funktionalen Äquivalenten in romanischen Sprachen. Beihefte zur Zeitschrift für Romanische Philologie, 338. Tübingen: Niemeyer

Wandruszka, Mario, (1976): Nuestros idiomas: comparables e incomparables, Madrid: Gredos.
Zuluaga Ospina, Alberto (1970), «La función del diminutivo en español», Boletín Instituto Caro y Cuervo, 25, 23-48.

\section{Notas}

1 «Nominalkonzepte können durch Einstellungen modifiziert werden, die psyschische Zustände ausdrücken. Anzunehmen ist eine ganze Skala von Einstellungen, die von besonderer Zuneigung über Mitgefühl bis zu ironischer Distanz reicht» (Motsch, 1999: 365).

2 Este autor distingue las sufijaciones hacia el objeto nombrado y hacia el interlocutor. Entre las primeras se encuentran los valores nocionales, emocionales, de frase (expresión del temple) y los estético-valorativos. Entre los segundos, los afectivo-activos, los de cortesía y los efusivos.

3 Según él, tenemos valores despectivos (discur sito), de débil temple afectivo positivo (cajita), «de ponderante valor afectivo, sin que, por ello, esté velado el significado propiamente diminutivo" (besitos, vocecita), de predominante sentido afectivo, «el significado diminutivo es velado por el contexto» (salito amplia), de sentido definitivamente afectivo «en sustantivos que significan persona más una predicación» (hermanito), de sentido afectivo en los vocativos o en los nombres propios (Aurelito), de efecto eufemístico (teticas) y por último el diminutivo lúdico. Zuluaga Ospina supone otros tres grupos más: superioridad condescendiente, familiaridad impertinente, y en función de «hijo de». Zuluaga Ospina, 1970: 43

4 Éstos distinguen cuatro valores: Palabra cariñosa: Mütterchen, Valoración: Das ist ein Weinchen, Ironía: Das ist ein Wetterchen, Infravaloración: Lass diese Witzchen, Späßchen! (Cartagena/Gauger, 1989: 233).

5 Para Klimaszewska serían los valores: expresión de cariño, sobre todo en el estilo indirecto $(\mathrm{Ma}$ machen), Verniedlichung (mach ein Schläfchen) en aquellos casos en los que el discurso tiene alguna relación con niños, eufemismo con función atenuante (Sie haben ein paar Feblerchen gemacht), infravaloración (Dichterlein), ironía (mein Freundchen) y particulares connotaciones expresivo emocionales (Erhataberein Köpfchen) (cf. Klimaszewska, 1983: 54-59).

6 Dressler/Merlini Barbaresi corroboran el valor nocional del sufijo diminutivo en, entre otros, condiciones específicas, en las que se utilizan en la derivación de sustantivos que ya designan, de por sí, una cantidad mínima.Con la finalidad de obtener un efecto intensificador estas construcciones se ayudan a veces de la negación: Es ist kein Stäubchen (Mehl) geblieben.(Dressler/Merlini Barbaresi, 1994: 84).

7 Según Waltereit (2006), estaríamos ante una relación metonímica, dado que entre las dos situaciones hay cercanía y esto se podría entender como la causa de traslado del sufijo diminutivo.

8 García Lorca (1957): Impresiones, Ganada, Obras completas, Aguilar, 3 ed, , 3.

9 En el lenguaje escrito se pueden observar partículas introductorias del tipo; Vaya...! o ; Me nudola...!, cuya función designará, con gran probabilidad una intención irónica (cf. Rainer 1993: 583). 